\title{
A PERSPECTIVA TRANSFORMATIVA NA ANÁLISE DE SIGNIFICADOS DE PRODUTOS DE TECNOLOGIA ASSISTIVA
}

\section{TRANSFORMATIVE RESEARCH ON MEANINGS ANALYSIS OF ASSISTIVE TECHNOLOGY PRODUCTS}

Marina Dias Faria

Universidade Federal do Rio de Janeiro - UFRJ Universidade Federal do Estado do Rio de Janeiro - UNIRIO marinafaria86@ hotmail.com

Leticia Moreira Casotti Universidade Federal do Rio de Janeiro - UFRJ leticia@coppead.ufrj.br

José Luis Felício dos Santos de Carvalho Pontifícia Universidade Católica do Rio de Janeiro - PUC Rio zkcarvalho@hotmail.com

Submissão: $21 / 03 / 2015$

Aprovação: 11/08/2015 


\title{
RESUMO
}

Alinhada à abordagem da transformative research, a pesquisa objetivou identificar e discutir significados atribuídos à mobilidade urbana e aos produtos de tecnologia assistiva que podem proporcioná-la. A investigação empírica comportou duas etapas: observação participante em oito cidades brasileiras e visita à maior feira de tecnologia assistiva do Brasil. A pesquisa traz resultados pouco explorados pela literatura com foco em consumidores deficientes: a percepção de que produtos de tecnologia assistiva podem ser sacralizados pelos consumidores; e a constatação de que, para certas organizações, vender produtos de tecnologia assistiva torna-se secundário diante da diretriz de construir uma identidade relacionada à cidadania corporativa.

Palavras-chave: Perspectiva transformativa. Tecnologia Assistiva. Mobilidade Urbana. Pessoas com deficiência.

\begin{abstract}
Aligned with approach of transformative research, the research aimed to identify and discuss meanings attributed to urban mobility and assistive technology products that can provide it. Empirical research included two stages: participant observation in eight Brazilian cities and visit the largest exhibition of assistive technology in Brazil. The research brings apparently uncommon results in the literature with a focus on disabled consumers: the perception that assistive technology products can be made sacred by consumers; and the realization that, for some organizations sell assistive technology products becomes secondary to the guideline of building an identity related to corporate citizenship.
\end{abstract}

KeyWords: Trasformative Research. Assistive Tecnology. Urban Mobility. People with disability. 


\section{Introdução}

Pesquisas com foco na exclusão social de pessoas com deficiências (doravante PcD) são relativamente frequentes em áreas do conhecimento como psicologia, turismo e educação. No campo da administração, entretanto, tais estudos são raros, ainda mais quando se trata de autores brasileiros (FARIA; CARVALHO, 2013). A despeito desse silêncio acadêmico, diversos aspectos relacionados à exclusão podem ser abordados em diferentes áreas do campo. Por instância, boa parte das pesquisas com foco em PcD em administração conduzidas por brasileiros (p. ex.: CAMPOS; VASCONCELLOS; KRUGLIANSKAS, 2013; LIMA et al., 2013; TETTE; CARVALHO-FREITAS; OLIVEIRA, 2013) ou por acadêmicos estrangeiros (p. ex.: JASPER; WALDHART, 2013; KONRAD et al., 2012) tratam de inclusão profissional. Na área de marketing, todavia, poucos acadêmicos brasileiros empreendem o movimento de retirar as PcD da frágil posição de indivíduos a mercê de uma sociedade excludente para alçá-los à categoria de consumidores (FARIA; SILVA, 2011). As dificuldades para inclusão de PcD no mercado consumidor ficam claras com a evidência de que tais indivíduos não conseguem frequentar os mesmos ambientes que os demais membros de seu grupo social, usualmente devido a problemas de mobilidade (HANISCH, 2011).

A questão da mobilidade urbana, foco do presente trabalho, apresenta grande relevância para pesquisas em marketing que tenham por foco os consumidores com deficiências, haja vista que barreiras de mobilidade costumam dificultar, ou até mesmo impedir, que PcD desempenhem o papel de consumidores (GANT, 2002; GOODRICH; RAMSEY, 2012; WANG; COLE, 2013). Outro aspecto que torna relevante a perspectiva de marketing sobre a mobilidade é a constatação de que as dificuldades enfrentadas por PcD para se locomover fazem com que elas busquem produtos oferecidos pela indústria da tecnologia assistiva, que se encontra em expansão (SMITH, 2005). Observe-se que o conceito de tecnologia assistiva é bastante amplo, podendo ser considerados como recursos assistivos bengalas que propiciem conforto para a locomoção, aparelhos auditivos ou mesmo carros adaptados às necessidades de uma pessoa com deficiência motora (MANZINI, 2005).

Não obstante a importância atribuída por $\mathrm{PcD}$ aos produtos projetados com tecnologia assistiva, poucos são os estudos que buscam compreender aspectos relacionados aos sentimentos e significados que esses recursos podem ter para tais consumidores. Pesquisas que versam sobre automóveis e $\mathrm{PcD}$, por exemplo, geralmente focam os aspectos técnicos relativos às adaptações necessárias para que o veículo possa ser conduzido por motoristas com deficiências (BOURHIS et al., 2002; PRASAD; HUNTER; HANLEY, 2006), porém são 
escassos os trabalhos acadêmicos nos quais subsiste a preocupação com o entendimento do significado da aquisição de um automóvel para PcD (MONACELLI et al., 2009; SCHMÖCKER et al., 2008). No que tange a produtos associados à mobilidade, são incomuns estudos como aquele desenvolvido por Smith (2005), que realizou observação focada no significado de cadeiras de rodas para consumidores com mobilidade reduzida, para os quais comprar a cadeira gera um sentimento comparável ao de se adquirir um novo corpo.

Em tal cenário, o objetivo da presente pesquisa foi definido como identificar e discutir significados atribuídos por pessoas com deficiências à mobilidade urbana e aos produtos de tecnologia assistiva que podem proporcioná-la. $\mathrm{Na}$ segunda etapa da parte empírica da pesquisa - que se seguiu a observações estruturadas em oito cidades brasileiras -, buscou-se replicar aspectos de coleta de dados utilizados por Smith (2005) em seu estudo conduzido em uma feira de tecnologia voltada para acessibilidade nos Estados Unidos. No presente trabalho, a investigação empírica ocorreu na maior feira de tecnologia assistiva já realizada no Brasil.

Diante desse quadro, é importante pontuar que o estudo não pretende apenas gerar informações relevantes para organizações interessadas em atender consumidores com deficiência; antes, porém, visa entender os significados da mobilidade e dos elementos aparentemente capazes de melhorá-la para $\mathrm{PcD}$, de modo a buscar proporcionar benefícios e bem-estar para tais pessoas. Ahuvia (2005) assevera que bens podem ter grande importância para o bem estar dos consumidores. A pesquisa aqui apresentada alinha-se, assim, à proposta da pesquisa transformativa (transformative research) proclamada inicialmente por Mertens (2007) e Mick (2006). A pesquisa transformativa surge da insatisfação com o modo pelo qual os paradigmas dominantes de pesquisa científica abordam temas relacionados a indivíduos socialmente desfavorecidos e/ou excluídos (CROCKETT et al., 2013; MERTENS, 2009). Para Mick (op. cit.), a adoção da perspectiva transformativa em marketing representa o primeiro passo para que a pesquisa do consumidor comece a pautar-se também para o benefício e para o bem-estar do ser humano, não apenas das empresas que disputam sua preferência como consumidor (OZANNE; DESCHENES, 2007).

\section{Revisão da literatura}

\section{Mobilidade urbana e pessoas com deficiências}

No âmbito do urbanismo, projetos de arquitetura costumam remeter à simplificação de considerar todos os indivíduos por meio de um falso padrão que desconhece a diversidade humana, para elaborar espaços que atendam somente a pessoas sem deficiências. Assim, são 
totalmente desprezados os deficientes, os indivíduos obesos, as pessoas de estatura muito alta ou muito baixa, e mesmo as pessoas que temporariamente se encontram fora dos parâmetros volumétricos corporais, como consumidores carregando compras ou mães com carrinhos de bebês (CAMBIAGHI, 2007).

As concepções de planejamento e desenho das cidades se baseiam na noção de um sujeito universalmente apto e não inclui indivíduos com problemas de mobilidade e que fogem a esse suposto padrão (AUDIRAC, 2008). Langan (2001) observa que tais modelos de urbanização levam em conta apenas a perspectiva médica da deficiência, que concebe o corpo deficiente sem levar em conta que não é o corpo mas sim o ambiente construído e as atitudes sociais que são os principais impeditivos à mobilidade. Imrie (2004) pondera que a deficiência é um fenômeno relacional em que as limitações funcionais apresentadas por uma PcD tornam-se incapacitantes como consequência de atitudes sociais restritivas e opressoras. Tais barreiras atitudinais refletem-se em diversas instâncias da vida em sociedade, inclusive nas atividades de consumo, e devem-se grandemente a processos de estigmatização.

Goffman (2008) pondera que a relação entre deficiência e identidade é responsável pelo impedimento a que as pessoas com deficiência possam gozar de uma plena aceitação social. Crosby (2012), por sua vez, argumenta que a estigmatização pode afetar significativamente o bem-estar físico, mental, afetivo e social de um indivíduo. Por outro lado, as atividades de consumo são capazes de criar e perpetuar estereótipos, bem como interferem em aspectos identitários e comportamentais. Por essa mesma razão, de acordo com a autora, as pessoas utilizam as práticas de consumo para gerenciar o estigma.

Sob essa perspectiva, Arnould e Thompson (2005) asseveram que consumidores podem ser concebidos como produtores de projetos identitários que eles próprios desenvolvem, utilizando os recursos materiais e simbólicos oferecidos pelo mercado. Assim, os consumidores podem ser tidos como atores sociais que participam de múltiplos mundos culturais, adotando valores e identidades subculturais específicas em cada um desses mundos. Nesse contexto, culturas de consumo podem ser definidas como arranjos sociais nos quais as relações entre os recursos sociais e a cultura, entre as formas de significação da vida e os recursos materiais e simbólicos dos quais eles dependem são mediados pelo mercado.

Bromley, Matthews e Thomas (2007) e Goodrich e Ramsey (2012) denunciam que a dificuldade que PcD têm para transitar pelos ambientes de mercado faz com que elas não estejam aptas a exercer diversos papéis sociais, inclusive de consumidores, e apontam o planejamento da mobilidade urbana como o fator mais determinante para a acessibilidade e a 
inclusão social. No que diz respeito à exclusão de PcD como consumidoras, a possibilidade de se locomover até os locais de consumo e dentro desses ambientes é fundamental para que tais indivíduos tenham autonomia, requisito básico para sua inclusão social (GANT, 2002). Estudos que corroboram essas informações indicam que a falta de acessibilidade nas ruas, nos meios de transporte e dentro dos locais de consumo é capaz de dificultar e até mesmo impedir que PcD exerçam o papel de consumidoras (GOODRICH; RAMSEY, 2012). Bauman (2008) assevera que frequentar templos de consumo é importante para a criação da identidade de um indivíduo, pois nesses lugares aconteceria a separação entre incluídos e excluídos, entre consumidores vistos como "inadequados" e "defeituosos".

A mobilidade urbana pressupõe que os meios de transporte devem funcionar de modo integrado e têm que ser acessíveis a todas as pessoas, requerendo que o usuário desfrute dos ambientes sem receber tratamento discriminatório por suas características pessoais (AGUIAR, 2010). Note-se que o governo desempenha um papel crucial tanto em aspectos relativos ao transporte quanto na manutenção e preservação de espaços, mobiliários e equipamentos urbanos (GANT, 2002; MELO, 2005). Um dos conceitos responsáveis pelo acirramento dos mecanismos de exclusão de PcD é a ideia de "espaços especiais" (cf. HALL; KEARNS, 2001), como "transporte especial", "banheiros especiais", "escolas especiais" e assim por diante, pois tais espaços circunscrevem a mobilidade dos deficientes dentro de limites geográficos definidos. Desejável seria que todos os espaços e meios de transporte proporcionassem condições iguais de mobilidade para os indivíduos com ou sem deficiências (BROMLEY; MATTHEWS; THOMAS, 2007).

Buscar diminuir problemas no âmbito da mobilidade urbana mostra-se relevante na medida em que tais problemas dificultam ou impedem que PcD participem de atividades fundamentais para a vida em sociedade, e que integram o cotidiano dos demais membros de suas comunidades: trabalho, educação, consumo, lazer, esporte, entretenimento, atividades religiosas, socialização com amigos, visitas a parentes e viagens (KENYON; LYONS; RAFFERTY, 2002). Os resultados da pesquisa de Hanisch (2011) com adolescentes com deficiências apontam que essas pessoas encontram diversas barreiras espaciais que impedem seu envolvimento em múltiplas atividades cotidianas. $\mathrm{O}$ primeiro passo para tentar amenizar tais problemas é compreender que PcD têm necessidades diferentes e, por isso, enfrentam problemas diferentes de mobilidade (DARCY, 2010).

Para usuários de cadeiras de rodas, por exemplo, as principais dificuldades no uso dos espaços urbanos são causadas por desníveis bruscos, escadas, rampas íngremes, pela limitação 
de seu alcance visual e manual, pela necessidade de contar com espaços amplos para girar a cadeira (CAMBIAGHI, 2007). As barreiras arquitetônicas são, portanto, as mais presentes nas vidas de pessoas com dificuldades de mobilidade que necessitam de uma prótese locomotora na forma de uma cadeira com rodas, e das demais pessoas com deficiências motoras. Os aspectos mais recorrentes são a falta de rampas e de banheiros adaptados (SASSAKI, 2003). Já pessoas com deficiência visual apresentam dificuldades para identificar objetos, detectar obstáculos e desníveis, determinar direções, seguir itinerários e identificar sinalização (CAMBIAGHI, op. cit.). Para tais pessoas, é imprescindível a implantação de superfícies táteis ao longo do meio-fio, principalmente nas proximidades dos pontos de parada e estações de transporte coletivo, em áreas adjacentes aos locais mais frequentados por tais usuários, bem como em áreas de travessia (TAKAMIYA; HAMADA, 1998).

\section{Recursos e produtos facilitadores da mobilidade}

Monacelli et al. (2009) defendem a prioridade de avanços tecnológicos capazes de propiciar uma melhor locomoção de $\mathrm{PcD}$ em planejamentos de políticas públicas e em diretrizes de empresas privadas. Na falta de políticas públicas e de ações privadas que promovam a mobilidade urbana, algumas $\mathrm{PcD}$ buscam melhorar sua mobilidade por meio de um conjunto crescente de produtos oferecidos por uma indústria em expansão: o setor da tecnologia assistiva, que, de acordo com Smith (2005, p. 18), vem sendo classificado por líderes de movimentos civis em prol dos direitos de PcD nos Estados Unidos como "o grande equalizador do século XXI".

Em contrapartida, o desenvolvimento da tecnologia assistiva e a difusão de produtos para melhorar a mobilidade vêm causando em alguns indivíduos a impressão de que são vistos pelos demais como metade humanos e metade máquinas (SMITH, 2005). Assim, de forma a negociar sua aceitação social, muitos indivíduos recorrem a práticas destinadas a humanizar e personalizar seus objetos de tecnologia assistiva, por exemplo, colando adesivos engraçados nas cadeiras de rodas ou usando muletas em cores alegres e vibrantes. Para a maior parte das pessoas, o corpo pode ser visto como um conjunto de peças isoladas, uma estrutura modular cujas partes podem ser substituídas para torná-la uma máquina impecável: aqueles que não se conformam com o corpo que têm buscam transformá-lo conforme a ideia que fazem dele (LE BRETON, 2009). Nesse sentido, o mesmo autor observa que, ao mudar o corpo, o indivíduo pretende mudar sua vida, modificar seu sentimento de identidade, o que condiz com a perspectiva de que fatores sociais e psicológicos - tais como a autoestima e o 
autoconceito - são relevantes no consumo de PcD (CARROLL; GROSS, 2010; CHANG et al., 2013).

Por outro lado, conforme argumenta Witt (2010), o consumo constitui uma prática sociocultural contingente há tempos reconhecida como atividade utilizada para significar status social, autoestima e pertencimento a grupos, o que talvez relegue a um âmbito secundário as características tecnológicas dos bens e serviços, pois o que realmente conta é sua capacidade de operar como símbolos. Nas palavras de McCracken (2007, p. 103), os bens de consumo, carregados de princípios culturais e valores simbólicos, "nos ajudam a compor o mundo culturalmente constituído, (...) organizam o mundo dos fenômenos e os esforços de uma comunidade para manipular esse mundo", configurando "tanto as criações como os criadores do mundo culturalmente constituído".

Sob essa ótica, acerca dos usuários de cadeiras de rodas, é preciso enfatizar que a cadeira não deve ser vista como mera coadjuvante na mobilidade, mas como uma ampliação do self e como uma extensão do corpo: algumas PcD se dizem intimamente violadas quando suas cadeiras são tocadas por pessoas não autorizadas. Para tais consumidores, comprar uma cadeira de rodas gera uma sensação comparável à de adquirir um novo corpo: a troca da cadeira de rodas por um novo modelo muda a altura e o peso da pessoa, modifica sua velocidade de trânsito e altera sua gestualidade (SMITH, 2005).

Outros produtos consumidos por PcD que podem ser analisados sob o prisma da mobilidade urbana são os automóveis adaptados, ou seja, carros que sofrem modificações em sua estrutura de funcionamento - geralmente nos pedais de freio, no acelerador e na embreagem - de acordo com as necessidades do deficiente, para que ele possa dirigir com segurança e comodidade. A dificuldade para a locomoção a pé, aliada à falta de acessibilidade no transporte coletivo, torna fundamental o carro para que uma $\mathrm{PcD}$ apresente autonomia no ambiente urbano (MONACELLI et al., 2009). Shand e Sivewright (1994) destacam que o estilo de vida da PcD modifica-se completamente depois da aquisição do carro adaptado.

A compra do automóvel parece associada ao desejo de independência por parte das PcD (RESENDE, CAVALCANTI; ANDRADE, 2012), em razão de o espaço urbano não ser acolhedor para elas (IWARSSON; STAHL, 2003; NICHOLL, 2001). Para adquirir um veículo automotivo, o consumidor com deficiência passa por um complicado processo de compra. Além das dificuldades relacionadas com o alto preço e com a pouca oferta do produto (MONACELLI et al., 2009), essas pessoas passam por uma minuciosa avaliação 
realizada por órgão reguladores governamentais até que seja definido que tipo de adaptação precisa ser implementada para viabilizar a direção (SHAND; SIVEWRIGHT, 1994).

Mesmo contando com os avanços dos recursos da tecnologia assistiva, como modelos modernos de cadeiras de rodas e carros com adaptações mais seguras, ainda são muitas as dificuldades de locomoção vivenciadas por $\mathrm{PcD}$, o que impacta no desempenho de seu papel como consumidores (MANZINI, 2005). Smith (2005) salienta que, para modificar o cenário de exclusão enfrentado por $\mathrm{PcD}$, é necessário que as empresas deem voz a essas pessoas, buscando entender suas reais necessidades, e que passem a considerá-las como potenciais consumidoras, inclusive incorporando-as a suas campanhas publicitárias. Para empresas que pretendem trabalhar pela inclusão, o primeiro passo é planejar o ambiente físico de consumo, porque a interpretação que PcD fazem do ambiente de loja é fundamental em suas escolhas de compra (PORIA; REICHEL; BRANDT, 2011; SHI, COLE; CHANCELLOR, 2012).

Pondera-se que mesmo se o poder aquisitivo das $\mathrm{PcD}$, as leis e as regulamentações fossem insuficientes para mobilizar organizações no sentido de estabelecer condições para sua inclusão no sistema de consumo, subsistiria o argumento de que empresas orientadas para a diversidade de clientes no tocante a PcD seriam detentoras de vantagem comparativa (HANASHIRO; GODOY, 2004). Para Cambiaghi (2007), investir em acessibilidade pode melhorar a imagem pública da empresa ao demonstrar que, além dos interesses econômicos, elas consideram aspectos éticos e sociais. Em acordo com a literatura sobre marketing de varejo, investimentos em acessibilidade de loja representam uma vantagem para a empresa, mesmo que seus clientes não sejam deficientes (KAUFMAN-SCARBOROUGH, 1998).

Em tempo, deve-se ressaltar que caracterizar os equipamentos de tecnologia assistiva como bens de consumo comuns pode configurar uma escolha ontologicamente questionável, haja vista que entidades de classe tais como o Conselho Federal de Fisioterapia e Terapia Ocupacional (COFFITO) advogam que esses produtos devem ser adquiridos e customizados a partir de prescrição clínica e monitoramento profissional (BRASIL, 2015), com base nos padrões de práticas para profissionais de Tecnologia Assistiva criados em 2008 pela Rehabilitation Engineering and Assistive Technology Society of North America (RESNA).

\section{Procedimentos metodológicos}

A parte empírica da presente pesquisa foi desenvolvida em duas etapas. Inicialmente, realizou-se uma etapa de coleta de dados no campo, pautada pelo objetivo de familiarizar os pesquisadores com aspectos de mobilidade urbana que influenciam diretamente o consumo 
praticado por PcD. Nessa etapa, foi empreendida observação simples estruturada, técnica em que o pesquisador especifica detalhadamente o que deseja observar e como vai registrar (LAVILLE; DIONNE 1999; MALHOTRA, 2006). Optou-se por registrar as observações por meio de notas de campo e de fotografias.

O foco das observações envolveu locais associados ao comércio varejista, tais como lojas de rua, galerias comerciais e shopping centers, bem como seu entorno. Foram conduzidas observações em localidades de destaque para o comércio varejista em oito cidades do Brasil, selecionadas por conveniência: Rio de Janeiro, São Paulo, Brasília, Campinas, Campo Grande, Belo Horizonte, Natal e Curitiba. Em alguns casos, os pesquisadores chegaram a permanecer dentro de estabelecimentos comerciais, em restaurantes ou em frente a vitrines de lojas por períodos de duas ou três horas consecutivas. Sempre que alguma situação despertava atenção, o momento era registrado por meio de fotos. Dois dos três autores da pesquisa realizaram essa etapa da coleta de dados ao longo de aproximadamente um ano e meio, e as 37 fotografias analisadas para a pesquisa - selecionadas a partir de mais de 200 fotos consideradas como material bruto - foram feitas pelos mesmos autores. Dados de observação e registros fotográficos foram debatidos em conjunto pelos três autores.

Loizos (2002) e Mendonça, Barbosa e Durão (2007) afirmam que o uso de fotografias proporciona objetividade e credibilidade a uma pesquisa, pois imagens fornecem evidências tangíveis sobre um dado fenômeno. Para Schulze (2007), a fotografia constitui uma técnica importante para acessar as interpretações que as pessoas fazem do ambiente sociotécnico, a partir das quais se pode oportunamente elaborar um guia para entrevistas. A técnica fotográfica parece se ajustar à pesquisa com PcD: por exemplo, Aldridge (2007) combinou as técnicas qualitativas da entrevista e da fotografia para pesquisar a exclusão de deficientes. Em razão do espaço destinado para a publicação, infelizmente tais fotografias não puderam ser incluídas no texto final do presente artigo.

Após essa primeira fase de registros fotográficos e notas de campo acerca de situações envolvendo mobilidade urbana e consumo de $\mathrm{PcD}$, foi realizada a segunda etapa empírica da pesquisa, com base no estudo realizado por Smith (2005) intitulado "Customize minha cadeira de rodas!: a oferta e demanda de cadeiras de rodas personalizadas”, em uma tradução livre de "Pimp my wheelchair!: the supply and demand for personalized wheelchairs", cuja investigação empírica ocorreu em uma feira de tecnologia voltada para acessibilidade. No caso de Smith, a feira visitada foi a Abilities Expo, um evento itinerante que acontece trimestralmente em diferentes cidades dos Estados Unidos. Na pesquisa aqui relatada, o 
evento que abrigou a segunda etapa do estudo de campo foi a $12^{\mathrm{a}}$ edição da ReaTech (Feira Internacional de Tecnologia em Reabilitação, Inclusão e Acessibilidade) que ocorreu em 2013 na cidade de São Paulo. A ReaTech é um importante evento internacional e, até o momento da coleta de dados para este trabalho, foi a maior feira de tecnologia assistiva já realizada no Brasil, com ampla participação institucional e empresarial, desde organizações representativas dos interesses de PcD, até grandes corporações, tais como FIAT e General Motors.

Assim como na pesquisa de Smith (2005), desenvolveu-se na feira ReaTech um estudo de campo com base etnográfica apoiado nas técnicas de observação participante e entrevistas. Adicionalmente, foi utilizado de novo o recurso da documentação fotográfica. Uma das pesquisadoras frequentou a feira por três dias consecutivos, participou de palestras e outras atividades, redigiu in loco um diário de campo acerca de suas observações sobre o evento, e realizou entrevistas que foram registradas em áudio e depois transcritas, não sem que antes o material bruto fosse apreciado por todos os autores. Ao todo, foram entrevistadas $30 \mathrm{PcD}$ presentes à feira - na maioria, indivíduos em cadeiras de rodas e, em menor número, pessoas com deficiências motoras que dispensam as cadeiras de rodas, e deficientes visuais - todos interessados nos itens expostos, além de 15 expositores que representavam organizações de portes diversos que comercializam produtos e serviços de tecnologia assistiva.

Todos os dados coletados na primeira e na segunda fases da pesquisa empírica foram submetidos à análise de conteúdo (BARDIN, 2011). De acordo com Woodrum (1984), análise de conteúdo refere-se a qualquer método utilizado para se fazer inferências por meio da identificação sistemática e objetiva de características específicas de mensagens, comunicações e produtos culturais que apresentem significados simbólicos latentes ou manifestos. Bauer (2002) salienta que, a despeito de, na maior parte das vezes, a análise de conteúdo ser realizada em materiais textuais escritos, procedimentos semelhantes podem ser aplicados a imagens, tais como fotografias e filmes, como também salienta Loizos (2002). White e Marsh (2006) ponderam que a análise de conteúdo pode ser aplicada a todos os tipos de textos, incluindo imagens e fotografias que interpretem uma realidade socialmente construída. Para Neiva-Silva e Koller (2002), a literatura consagrou a análise de conteúdo como técnica relevante para analisar material fotográfico em pesquisa científica desde o ano de 1890, num estudo que teve indivíduos cegos e surdos como sujeitos de pesquisa.

Para a representação dos resultados, optou-se por preservar as contribuições oriundas das duas etapas da pesquisa, porém integrando os resultados da primeira etapa aos da segunda etapa, de modo a complementar as entrevistas realizadas na feira de tecnologia assistiva com 
os dados das fotografias e das observações. Assim, inicialmente são consideradas as fotos e os registros das observações, com o objetivo de traçar um panorama compreensivo das questões envolvendo mobilidade urbana e PcD no mercado, para que posteriormente sejam analisados os dados observados e coletados por meio de entrevistas na feira ReaTech. As duas etapas guardam, portanto, uma íntima relação e não devem ser apreciadas de maneira independente.

\section{Representação e discussão dos resultados}

\section{Retrato de um mercado sem mobilidade para PcD}

Tomando-se por parâmetro os exemplos de locais de varejo nas oito cidades brasileiras em que foram registradas observações - bem como de seus entornos e das principais alternativas de transporte para acessá-los - pode-se reafirmar que a falta de mobilidade impacta sobremaneira no desempenho do papel de consumidores por parte de PcD (GANT, 2002; GOODRICH; RAMSEY, 2012). Em alguns casos, foi possível notar que tais consumidores ficam impedidos até mesmo de entrar nos estabelecimentos comerciais; em diversas lojas, por exemplo, há degraus intransponíveis na entrada. Registrou-se por foto como resultado desse tipo de barreira arquitetônica que o consumidor deficiente tende a desistir de entrar no estabelecimento. Em algumas situações, foram fotografados vendedores que saem das lojas para atender a tais consumidores nas calçadas, improvisando uma “solução" longe do ideal, uma vez que essa ação impõe a separação entre consumidores com e sem deficiência, o que parece contribui para a exclusão social (BAUMAN, 2008).

Barreiras arquitetônicas para adentrar ambientes de consumo foram observadas até mesmo em estabelecimentos nos quais sua presença parece disparatada, como, por exemplo, em uma concessionária de automóveis que comercializa carros adaptados para $\mathrm{PcD}$, na qual há apenas uma entrada e existe uma escada sem acessibilidade. $\mathrm{O}$ exemplo mostra que, mesmo em ocasiões nas quais a PcD configura o público-alvo da empresa, tais consumidores não têm atendidas suas demandas mais simples. Outra fotografia mostra uma usuária de cadeira de rodas tendo que ser carregada para entrar em um edifício comercial.

Nas poucas vezes em que os consumidores deficientes conseguem transpor as barreiras à mobilidade nas ruas, nas calçadas e nas entradas das lojas, eles precisam contar com a boa vontade de vendedores e outros consumidores para circular dentro dos ambientes de varejo quando a loja é muito apertada para que a cadeira de rodas possa circular. Os provadores de roupas também não costumam apresentar o tamanho adequado para a utilização pelos usuários de cadeiras de rodas, não obstante tal problema já ter sido detectado pela 
literatura acadêmica em marketing há mais de quinze anos (ver: KAUFMANSCARBOROUGH, 1998). Outro registro fotográfico efetuado para a presente pesquisa mostra um elevador para pessoas com mobilidade reduzida servindo como depósito para mercadorias, em uma loja de uma das maiores cadeias varejistas do país.

Outros problemas registrados em fotografias na presente pesquisa dizem respeito à arrumação dos produtos nas lojas: em São Paulo e no Rio de Janeiro, roupas penduradas em locais elevados são inacessíveis para pessoas em cadeiras de rodas, e cabideiros lotados são de difícil manuseio para deficientes visuais. Todas essas barreiras podem ser tomadas como razões para que PcD desistam de desempenhar o papel de consumidoras e o deleguem para outras pessoas, conforme alertaram Bromley, Matthews e Thomas (2007) e Goodrich e Ramsey (2012).

Os registros fotográficos nas oito cidades pesquisadas corroboraram a literatura no que se refere à constatação de que as dificuldades enfrentadas pelas PcD para engajar-se em atividades de consumo principiam com os problemas nas alternativas de transporte que as conduziriam até os ambientes de varejo (cf. GANT, 2002). Há problemas estruturais como ônibus que, apesar de contarem com o adesivo indicativo de acessibilidade, não possuem qualquer tipo de adaptação, o que torna impossível sua utilização por indivíduos com deficiência motora ou visual. Em algumas cidades foram registradas situações que evidenciam também a falta de preparo dos prestadores de serviço nos transportes coletivos: muitos motoristas recusam-se a parar nos pontos de ônibus quando vislumbram uma PcD esperando para embarcar. A importância dos motoristas para a mobilidade urbana de PcD já foi apontada por acadêmicos estrangeiros (CROOKS, DORN;WILTON, 2008), e parece ganhar relevância quando se trata de mobilidade em grandes cidades brasileiras.

Barreiras atitudinais decorrem de problemas no comportamento da sociedade quanto à mobilidade: como exemplo, registrou-se uma deficiente visual que só conseguiu acomodar-se no assento reservado a $\mathrm{PcD}$ em um ônibus do Rio de Janeiro porque um passageiro obrigou outro a levantar-se do assento preferencial; o mesmo passageiro se ofereceu para avisar quando chegasse o ponto no qual a deficiente desejava descer, pois não havia nenhum aviso sonoro no veículo. Fora dos meios de transporte, perpetuam-se as barreiras arquitetônicas. A falta de conservação e de sinalização das calçadas impede que PcD se locomovam até mesmo para lugares próximos de suas residências. Com exceção de Campo Grande, em que foi observado piso tátil (próprio para identificação de rotas para deficientes visuais) em quase todas as calçadas, pode-se aventar que PcD optam por sair de casa só em situações de extrema 
necessidade. Mesmo nessa cidade, em que o poder público obriga o responsável pela calçada a mantê-la conservada e sinalizada, registram-se críticas de lojistas quanto a investir em pisos táteis. Fotografias feitas na cidade de Natal mostram que algumas calçadas tem piso tátil, mas o péssimo estado de conservação, com muitos buracos, impede a circulação de PcD.

\section{Mobilidade urbana: independência versus exclusão social}

A palavra "independência" foi recorrente nas entrevistas e, não por coincidência, também foi observada em diversos banners das empresas expositoras na feira. Acima de tudo, PcD parecem buscar independência quando adquirem um recuso de tecnologia assistiva, seja uma cadeira de rodas ou uma bengala para deficientes visuais. Tal busca parece associada à percepção, unânime entre os sujeitos, de que as cidades não oferecem condições mínimas de mobilidade para pessoas socialmente estigmatizadas como sendo "fora do padrão", contrariando a corrente arquitetônica do desenho universal, ou seja, a ideia de que um produto deve ser disponibilizado no mercado apenas quando se adequa ao uso por corpos de todos os tipos (CAMBIAGHI, 2007).

- É muito ruim depender de outras pessoas. E com a cidade que temos, ou melhor, o país, fica difícil se locomover por aí. Por isso tem que ser independente, custe o que custar. Não tem como ser (independente) sem ter mobilidade.

Melhorias na mobilidade urbana são ansiadas por muitos respondentes que, no entanto, acreditam ser um sonho distante pensar em grandes cidades brasileiras acessíveis. Para mudar essa realidade, os entrevistados apontaram ser necessário haver vontade do poder público, e muitos enfatizaram que não é possível esperar nada de empresas privadas.

- Estamos nas mãos dos políticos. Porque se depender de empresas privadas, estamos em maus lençóis. Deficiente não dá lucro.

- (As empresas privadas) querem lucro e nós não parecemos ser lucrativos. Mas precisamos de mudanças urgentes nas configurações das cidades.

Os resultados também mostraram que projetos públicos de melhoria de mobilidade urbana são considerados muito importantes para a autonomia de PcD. Os sujeitos destacaram que de nada adianta buscar melhorias em educação inclusiva, por exemplo, se nada for feito para melhorar as condições de deslocamento nas cidades. Como evidencia o depoimento a seguir, a falta de independência causada por problemas de mobilidade urbana é percebida pelos sujeitos como diretamente associada à exclusão social. 
- Não dá para saber o que vem primeiro. Querem que a gente acredite que nós, deficientes, acabamos ficando excluídos porque não temos como nos locomover por cauda dos problemas de mobilidade urbana. Mas, de verdade, o que ocorre é que somos excluídos socialmente, por isso ninguém se importa com os problemas que nos afetam, inclusive a falta de mobilidade urbana.

Acadêmicos que anteriormente se debruçaram sobre questões de exclusão e mobilidade urbana trataram o primeiro fenômeno como consequência de problemas estruturais de mobilidade, tais como calçadas em mau estado de conservação e transporte não inacessível (p. ex.: BROMLEY; MATTHEWS; THOMAS, 2007; GOODRICH; RAMSEY, 2012). Na presente pesquisa, os entrevistados parecem crer que se trata de um ciclo mais complexo: segundo os sujeitos, subsiste o descaso com os problemas de mobilidade urbana porque deficientes são tratados como excluídos, não como cidadãos; por sua vez, a exclusão traz a impressão de que não é preciso criar condições para que essas pessoas possam circular livremente, já que elas "ficam mesmo é em casa".

- É comum ouvir que não tem rampa ou não tem piso tátil em determinados locais por que as pessoas com deficiência não iriam mesmo. Não existe lugar para nós, porque somos excluídos.

Diante de depoimentos assim, pode-se perceber que espaços urbanos acessíveis têm uma grande importância para $\mathrm{PcD}$, e adquirem, segundo os sujeitos, significados de "vitória social", "conquista de independência" e "igualdade". Cabe destacar que o espaço no qual foi realizado a feira ReaTech foi modificado para o evento, de modo a apresentar acessibilidade, pois o espaço não é acessível normalmente: foram instaladas rampas, pisos táteis e sinalizações em Braille, e mesmo para chegar à feira as $\mathrm{PcD}$ tiveram que contar com transporte especial, já que o transporte coletivo de São Paulo não atendeu às necessidades dos participantes. Uma vez mais, nota-se que, cotidianamente, $\mathrm{PcD}$ não encontram condições adequadas de mobilidade para desempenhar seus papéis sociais, conforme apontado em estudos anteriores, como aquele conduzido por Gant (2002).

\section{Significados associados à cadeira de rodas}

Cientes da eterna busca por autonomia por parte de PcD, bem como de sua relação direta com a mobilidade, as empresas expositoras estampam em seus estandes na feira ReaTech promessas de independência para quem vier a adquirir seus produtos e serviços. Imagens de buracos em calçadas são reproduzidas nos estandes, para lembrar aos visitantes 
como é precária a estrutura urbana; em contraposição, os expositores demonstram como os produtos ofertados podem proporcionar independência por melhorarem a mobilidade.

Vários recursos de tecnologia assistiva estavam expostos na feira, mas as cadeiras de rodas eram certamente os itens de maior destaque, e mais celebrados pelos deficientes motores. Além da percepção da cadeira de rodas como parte do corpo pelos usuários, conforme demonstrou previamente a pesquisa de Smith (2005), aqui os sujeitos atribuíram ao objeto o status de "irmã", "melhor amiga" e "minha vida". De certa forma, já se esperavam depoimentos que apontassem a grande importância da cadeira de rodas na vida de pessoas com deficiência motora, mas despertou atenção o fato de a cadeira de rodas também parecer ter significados especiais para indivíduos com outros tipos de deficiência.

- Eu tenho uma grande inveja de quem pode ter uma cadeira de rodas. É uma amiga. Para mim não tem nada assim. Tenho admiração por esse objeto, não me canso de olhar os modelos.

- Olha essa (cadeira de rodas): é a solução das vidas das pessoas que têm deficiência motora. É tipo um milagre. Eu não tenho isso. A bengala talvez. Mas não é tão importante. É assim... a bengala traz uma pequena felicidade, mas a cadeira de rodas é a solução de tudo relativo à movimentação na cidade.

Concedidos por deficientes visuais observados adentrando todos os estandes com cadeiras de rodas na feira, os depoimentos anteriores demonstram o fascínio que tal produto pode exercer mesmo em pessoas com deficiências que não a motora. O deslumbramento era ainda maior por parte dos deficientes motores. Nos estandes dos expositores que vendiam cadeiras de rodas, era possível observar muitos usuários encantados com as novidades, muitos deles investindo tempo para conferir cada detalhe das cadeiras. Aquelas que pareciam despertar mais desejo eram as que prometiam ser capazes de transpor barreiras como meiosfios altos e calçadas esburacadas, permitindo que o usuário "andasse como qualquer um".

- (Cadeira bonita) é legal, mas o que importa pra gente que mora aqui em São Paulo, nessa loucura, é uma cadeira que saiba subir meio-fio enorme, e que não quebre diante do primeiro buraco. Tenho que ter tanta capacidade de andar quanto qualquer outra pessoa, e a cadeira é o meio para isso.

$\mathrm{Na}$ esperança de que a cadeira de rodas traga a tão sonhada independência, as pessoas com deficiência motora parecem atribuir um significado especial a esse recurso, que acaba ganhando status de sagrada em alguns casos. Tal sacralização - característica de uma modalidade particular de materialismo pela qual o consumidor associa aspectos 
espiritualmente elevados de sua felicidade à posse de um produto (PACE, 2013) - parece vir acompanhada do fato de tais indivíduos estarem dispostos a pagar preços altos pelo bem, mesmo quando os recursos financeiros não se acham disponíveis.

- A minha cadeira de rodas é como se fosse um anjo na minha vida. Sem ela, não sou ninguém. Pago o quanto for em uma boa.

- É Deus no céu e minha cadeira na terra.

- Fico todo endividado toda vez que venho nessa feira, compro o último modelo. Eu mereço. Não compro nada caro, não viajo, não compro roupa de marca, nada importa, mas uma boa cadeira, sim. Minha cadeira é minha identidade.

Conforme havia sido aventado por Le Breton (2009), o último depoimento aponta para uma constatação confirmada por vendedores de cadeiras de rodas: a cadeira é associada à identidade das pessoas com deficiência motora, por elas mesmas, e por outros também. O produto adquire assim uma importância enorme e sua escolha angaria complexidade, pois um erro pode ser prejudicial à imagem que o usuário de cadeira de rodas deseja transmitir.

- Elas passam horas aqui olhando os mínimos detalhes. Vários já me disseram que a cadeira fala quem eles são, por isso têm que escolher bem. Depois que perguntam tudo, ainda fazem comparações e só compram quando têm certeza. Também tem o outro lado. Tem uns que batem o olho e falam: "Pronto! Essa é a minha cara!'. Quando acham essa, compram, custe o que custar.

\section{Recursos de tecnologia assistiva para deficientes visuais}

Conforme exposto na subseção anterior, os deficientes visuais apresentaram atitudes positivas com relação a cadeiras de rodas, mesmo não sendo usuários do recurso. No caso dos produtos de tecnologia assistiva para melhorar a mobilidade desse grupo de consumidores, o sentimento associado parece ser, quase sempre, a frustação, cujas causas geralmente são atribuídas a dois fatores: (1) o descaso de empresas e do governo, que não disponibilizam recursos de tecnologia assistiva; e (2) a pouca efetividade dos recursos disponíveis.

No que tange à primeira causa, verificou-se que diversos expositores utilizam folhetos explicativos para ensinar aos deficientes sobre as leis, de modo a incentivá-los a cobrar dos estabelecimentos comerciais e do governo que disponibilizem os recursos necessários. Esse movimento por parte de empresas que comercializam pisos táteis e cardápios em Braile parece ser importante, visto que o desconhecimento das leis relativas à acessibilidade parece ser grande tanto por parte de PcD quanto das empresas (HANASHIRO; GODOY, 2004). 
- (Os deficientes visuais) têm que aprender a cobrar os seus direitos. Pra gente (empresa que vende piso tátil) poder vender. Muitos não sabem que podem cobrar.

- Muitas vezes a empresa não coloca o piso tátil porque não quer, mas muitas vezes é porque nem sabe para que serve aquele emborrachado com bolinhas e tracinhos.

Já recebemos pedidos de empresas que queriam colocar como enfeite.

O piso tátil, tão pouco presente nas ruas e em estabelecimentos comerciais, pode facilitar o deslocamento de pessoas com deficiência visual, razão pela qual foi recorrente a expressão de liberdade e independência que pode ser proporcionada pelo recurso.

- Não custa nada ter o piso tátil. E para nós é mais do que um recurso: é a única chance que temos de ter uma certa liberdade. Em lugares que têm o piso, eu posso andar com minha bengala sem ajuda de outra pessoa.

As bengalas constituem outro recurso importante para deficientes visuais. Todavia, apesar de serem caracterizadas por seus usuários como "companheira" e "parte do corpo", as bengalas não parecem ter significados positivos para aqueles que precisam usá-las. Elas também fazem parte do corpo dos deficientes, o que as torna parte de suas identidades (LE BRETON, 2009), no entanto, as bengalas reforçam a "identidade de deficiente" de seus usuários, o que parece fazer emergir sentimentos negativos com relação ao produto.

- Quem me vê na rua com a bengala já fala: "Lá vai o ceguinho”. Odeio!

As observações mostraram que as empresas expositoras que comercializam bengalas tentam quebrar essa atitude, buscando transformar a bengala em um acessório. Para tanto, disponibilizam bengalas de diversas cores e formatos, e estabelecem comparações com óculos e até mesmo com joias no esforço da venda. Diante da resistência por parte dos deficientes, o apelo mais eficaz é aquele que reforça a funcionalidade da bengala para melhor a mobilidade. Além de reforçar o estigma da deficiência, a bengala recebe críticas também por não ser considerada muito efetiva como recurso auxiliar na mobilidade, reforçando a dependência das pessoas com deficiência visual, mesmo quando elas recorrem às bengalas.

- De que me adianta a bengala se não tem piso tátil? Antes da bengala tocar na base do orelhão (telefone público), eu já enfiei a cabeça nele. Não me traz independência, continuo precisando de outras pessoas.

Estabelecendo-se um confronto entre esta subseção de representação dos resultados da pesquisa com a subseção precedente, chega-se a um fato curioso envolvendo dois produtos de tecnologia assistiva relacionados à mobilidade. Enquanto a cadeira de rodas assume um significado sacralizado por indivíduos com deficiência motora, a bengala incorpora um 
significado predominantemente negativo para sujeitos com deficiência visual. Tal oposição evidencia a amplitude de significados atribuídos a produtos utilizados na locomoção e/ou na motricidade de PcD. Pode-se aventar que produzir e oferecer ao mercado um produto que proporcione ou incremente a mobilidade não significa que os usuários venham necessariamente a se afeiçoar ao produto ou a manifestar uma atitude favorável com relação às empresas que os fabricam e comercializam.

\section{Tecnologia assistiva: um segregador social?}

Mesmo antes de realizar as entrevistas foi possível perceber, logo na entrada da feira, que os consumidores com deficiências ficam animados para descobrir os novos lançamentos da indústria capazes de ajudar em sua mobilidade. Para esses consumidores, a feira é o momento de conhecer novidades, o que gera bastante excitação, mesmo que o produto eventualmente não possa ser adquirido em razão do preço.

- Eu adoro ver as novidades. As cadeiras mais avançadas me fascinam. Sei que nunca vou poder comprar essas mais completas, mas só de saber que existem eu já fico feliz. É como se me desse algo com o que sonhar. Sei que parece pouco, mas sonho de "cadeirante" é uma cadeira boa.

Esse tipo de construção textual, que foi recorrente nas entrevistas, parece indicar que, por mais que muitas vezes os recursos de tecnologia assistiva pareçam ser responsáveis por uma separação entre as $\mathrm{PcD}$ com alto poder aquisitivo e aquelas com baixo poder de compra, esses produtos exercem um papel importe como motivadores, mesmo para quem não pode adquiri-los. Alguns sujeitos, no entanto, fizeram questão deixar de claro que esses recursos não podem ser tomados como soluções definitivas para os problemas de mobilidade, exatamente por não estarem ao alcance de todos. Essa visão reforça a importância de que o desenho das cidades contemple espaços públicos que democraticamente atendam as demandas das PcD; o que se observa, entretanto, é exatamente o contrário: projetos de urbanização que se baseiam somente nas habilidades de corpos perfeitos (AUDIRAC, 2008; CAMBIAGHI, 2007).

Nas entrevistas com vendedores presentes nos estandes de concessionárias de automóveis na feira foi possível perceber que essas empresas reconhecem e reforçam a ideia de que os recursos de tecnologia assistiva atendem apenas a poucas pessoas.

- É caro mesmo. Não tem jeito. É algo muito exclusivo. Tem... como posso dizer?

Alto valor agregado. Então tem que ser caro. É, não para todos, mas o que é? 
- Vou ser sincera, não é para banalizar o produto. Ficaríamos conhecidos como o carro de pessoas com deficiência. Não queremos. Não somos marca de deficiente.

Essa última fala apresenta uma forte razão para a restrição de acesso a automóveis adaptados, a qual em geral fica encoberta pela questão financeira. $\mathrm{O}$ mais comum é que se atribua o fato de somente uma pequena parcela de $\mathrm{PcD}$ possuir carros adaptados a fatores tais como a desinformação sobre incentivos fiscais e o alto custo dos automóveis (MONACELLI et al., 2009). No presente estudo, outrossim, levanta-se a suspeita de que parece ser parte da estratégia das grandes montadoras de veículos não focar em atender esse público, de modo que a corporação não fique conhecida como "marca de deficiente". Depois de algum tempo de conversa, os representantes das empresas presentes à ReaTech, inclusive da montadora responsável pela concessionária fotografada na primeira etapa da pesquisa por não possuir acessibilidade a despeito de vender carros adaptados, emitiram depoimentos que comprovam tal preocupação e, em alguns casos, ficou claro que a participação na feira também é parte da estratégia das empresas e guarda pouca relação com a comercialização de carros adaptados. Em alguns casos, fica evidente a enunciação de barreiras atitudinais por parte dos respondentes, como na segunda fala abaixo apresentada, em que o informante discorre sobre a necessidade de "marcar presença" na feira.

- Aí você pode me perguntar: se vocês não têm esse foco de vender para PcD, por que vocês estão aqui nessa feira? Simplesmente porque temos que estar. Porque isso é bem visto, tiramos fotos do nosso espaço aqui e os outros clientes gostam. É responsabilidade social. Fundamental hoje.

- Temos que marcar presença. Se não estivermos aqui, somos mal vistos pela sociedade. Não precisamos vender.

Somente em estandes de organizações não governamentais (ONGs) foi possível registrar o discurso de que os recursos de tecnologia assistiva devem ser usados com o intuito de promover a inclusão social. Nesses casos, notou-se a defesa do argumento de que todos os cidadãos têm que ter acesso a tais recursos, e de que é papel do governo proporcionar condições adequadas de mobilidade urbana. No que diz respeito à questão da suposta reponsabilidade social corporativa com respeito à inclusão, quando questionados acerca do papel das empresas privadas, os representantes das ONGs afirmaram que não têm nenhuma esperança de que elas ajudem a resolver efetivamente o problema.

- Não dá lucro. É somente isso. Deficientes não são lucrativos, não adianta. Não vai atrair empresa privada. Tudo isso aí que você está vendo aí na feira? Fachada. 
Caso correspondam à disposição predominante por parte da iniciativa privada, depoimentos como esse último reforçam a perspectiva utilitarista que os empresários atribuem aos consumidores e, infelizmente, descartam os deficientes como consumidores a serem vistos como um segmento passível de ser condignamente atendido na arena de mercado.

Cabe alertar para o fato de que o movimento aqui empreendido, de atribuir à tecnologia assistiva uma faceta associada à segregação social pode eventualmente ser tomado como arriscado, pois a definição correspondente é deveras abrangente, não se restringindo a uma cadeira de rodas ou a uma bengala cujo preço de exposição em uma feira seja considerado alto por consumidores interessados no item. Note-se que o termo tecnologia assistiva refere-se, outrossim, a "produtos, recursos e serviços especificamente projetados (...) com objetivo de prevenir, compensar, ou neutralizar deficiências, limitações na atividade ou restrições na participação, e melhorar a autonomia e a qualidade de vida" (MAIA; NIEMEYER; FREITAS, 2010, p. 63). Por vezes, preços de produtos percebidos como elevados podem refletir investimentos privados em tecnologias agregadas ao produto, mas outras vezes não.

\section{Considerações conclusivas}

Endossando a proposta epistemológica da transformative research, a presente pesquisa foi norteada pelo objetivo de identificar e discutir significados atribuídos por pessoas com deficiências à mobilidade urbana e aos produtos de tecnologia assistiva que podem proporcioná-la. Para a segunda etapa referente ao estudo de campo, referente à realização de entrevistas e observações na feira ReaTech, assim como para a interpretação dos resultados, foi fundamental uma etapa inicial de observação e registro fotográfico de situações envolvendo PcD e mobilidade urbana em grandes cidades brasileiras.

Essa primeira etapa evidenciou que muitas são as barreiras à mobilidade, e que grande parte delas tem natureza arquitetônica, ou seja, apresenta causas associadas a questões estruturais da cidade, porém desvelou barreiras atitudinais, criadas por questões de relacionamento entre $\mathrm{PcD}$ e a sociedade em geral. Aqui se deve chamar a atenção para o fato de que a verdadeira inclusão se produz, sobremaneira, a partir da combinação efetiva de ao menos três elementos: investimentos em mobilidade urbana, acesso à tecnologia assistiva $\mathrm{e}$ remoção das barreiras atitudinais.

A pesquisa traz dois resultados aparentemente incomuns e pouco explorados na literatura nacional e estrangeira na área de marketing com foco em consumidores com deficiências. Em primeiro lugar, o estudo empírico levantou a questão de que, além de serem percebidos como partes indissociáveis dos próprios corpos dos indivíduos que deles se valem 
para angariar mobilidade, alguns produtos de tecnologia assistiva - em especial as cadeiras de rodas - podem ser sacralizados pelos consumidores deficientes, não somente por seus usuários, como também por indivíduos cujas deficiências nem sequer podem ser amparadas por tais recursos. Segundo, os resultados do campo sugerem que, para algumas organizações, em um contexto no qual ações alegadamente atreladas à responsabilidade social parecem representar acima de tudo uma ferramenta para fomentar uma imagem empresarial identificada pelo mercado como socialmente benéfica (POMERING; JOHNSON; NOBLE, 2013), vender produtos de tecnologia assistiva constitui uma meta secundária diante da diretriz estratégica de construir uma identidade de marca relacionada à cidadania corporativa. À guisa de recomendação para futuros estudos, sugere-se examinar esses dois resultados, dos quais se poderia levantar a proposição de que particularmente o segundo seja mais pronunciado no mercado brasileiro.

Os demais achados desta pesquisa recuperam a reflexão sobre o predomínio da visão médica da deficiência em detrimento da social (cf. LANGAN, 2001), haja vista que os resultados explicitam que o espaço urbano não oferece bem-estar para $\mathrm{PcD}$, porém, ao mesmo tempo, considera-se normal que o mobiliário urbano seja criado para atender a um hipotético homem desprovido das assim denominadas deficiências, o qual não condiz com o planejamento urbano voltado para o desenho universal, que finalmente parece existir apenas em teoria. A situação se agrava quando se considera que, mesmo quando há recursos capazes de amenizar os problemas de mobilidade, eles são cruelmente caros e, portanto, inacessíveis para a maioria dos deficientes.

Nesse contexto, a falta de mobilidade urbana traz algumas consequências negativas para a prática do consumo por parte de $\mathrm{PcD}$, muitas das quais foram efetivamente narradas pelos sujeitos da presente pesquisa: (1) o alto investimento em locomoção desvia o dinheiro dos locais de consumo para os meios de transporte utilizados para se chegar a esses locais; (2) a baixa mobilidade urbana cria uma dependência da PcD em relação a seus familiares, impedindo que ela possa consumir livremente; (3) os entraves à mobilidade provocam um encarceramento da PcD em sua residência, fazendo com que seu consumo restrinja-se a bens e serviços ofertados pela internet e consumidos em casa; e (4) a busca vã por produtos de tecnologia assistiva acessíveis às necessidades de cada $\mathrm{PcD}$ e a todos os bolsos educa o consumidor deficiente a resignar-se em sua decepção com as empresas que disputam sua preferência, as quais deveriam ampará-los em suas carências, mas acabam por decepcioná-lo constantemente, fomentando um permanente estado de insatisfação decorrente do consumo. 
Diante do cenário de descaso com as necessidades dos deficientes no que diz respeito à mobilidade urbana, fica mais fácil dimensionar a importância que tais indivíduos concedem a recursos que possam melhorar sua situação. Em busca da tão sonhada independência proporcionada por condições melhores de mobilidade, PcD atribuem uma importância enorme aos recursos de tecnologia assistiva relacionados à mobilidade e parecem desenvolver por muitos deles afetos significativos. Note-se, entretanto, que os resultados da pesquisa mostram que nem sempre os sentimentos e significados atribuídos aos recursos de tecnologia assistiva voltados para mobilidade são positivos: por vezes, recursos que de algum modo reforçam a identidade social do deficiente são tidos como seu "pior pesadelo" ou "inimigo número 1". Assim, é fundamental entender que diferentes recursos podem ter significados opostos para PcD. As bengalas, por exemplo, costumam ter significados negativos, enquanto as cadeiras de rodas são tidas como salvações e formas de camuflar a deficiência.

Como pano e fundo para a análise aqui empreendida, podem-se depreender alguns questionamentos perturbadores. Por exemplo, de que adianta para um consumidor com deficiência ter acesso a produtos assistivos de alta tecnologia, se a mobilidade urbana não permite seu uso, numa sociedade que estigmatiza como incapaz o usuário? Com a ajuda de pisos táteis, talvez uma bengala possa substituir a visão de um deficiente visual, da mesma forma que uma cadeira de rodas possibilita a acessibilidade arquitetônica para quem tem dificuldades de locomoção; porém, há indícios de que a evolução tecnológica dos produtos assistivos pode não ser suficiente para superar os lentos avanços na mobilidade urbana, muitos dos quais melhor poderiam ser caracterizados como retrocessos, se apreciados em conjunto com os mecanismos de exclusão social estruturados em barreiras atitudinais.

De qualquer modo, tomados em conjunto, os resultados da pesquisa indicam haver oportunidades para um expressivo crescimento da indústria de produtos de tecnologia assistiva no Brasil, principalmente com relação a produtos relacionados à mobilidade. Curiosamente, a despeito dos indícios de que pode ser profícuo para as empresas atender a demandas de $\mathrm{PcD}$, poucas organizações optam por esse mercado. Como se mencionou anteriormente, igualmente raros são os acadêmicos de marketing que se interessam pela questão. A escassez de estudos sobre veículos adaptados (BOURHIS et al., 2002; PRASAD; HUNTER; HANLEY, 2006), por exemplo, parece traduzir o desinteresse das montadoras por esses produtos em seu portfólio, exceção feita para a preocupação em disponibilizar algumas unidades de produtos que reflitam uma aparente preocupação social. Novos esforços de pesquisa podem dedicar-se a investigar as causas pelas quais se propaga certa resistência por 
parte de muitas empresas em fabricar produtos adaptados para $\mathrm{PcD}$, apesar dos possíveis ganhos financeiros advindos de uma efetiva exploração desse mercado em expansão.

Em consonância com a transformative research (CROCKETT et al., 2013; HEATH; CHATZIDAKIS, 2012; MICK, 2006), o presente estudo tem sua relevância acrescida por denunciar questões que, em geral, são contempladas apenas sob a perspectiva das empresas, mas que, quando adequadamente endereçadas, podem contribuir tanto para otimizar a ação da iniciativa privada quanto para melhorar a vida das PcD. Como exemplo, tem-se a exclusão por meio da posse ou da falta de produtos de tecnologia assistiva. Sob a ótica hegemônica em marketing, uma maior oferta desses produtos precisaria ser justificada por meio de uma promessa de mais lucro para os acionistas; em trabalhos como o presente, que seguem a perspectiva transformativa, o fato de a maior oferta melhorar a vida dos consumidores com deficiências é suficiente para ensejar mudanças por parte das empresas e do poder público. 


\section{REFERÊNCIAS}

AGUIAR, F. Acessibilidade relativa dos espaços urbanos para pedestres com restrições de mobilidade. 2010. 190 folhas. Tese (Doutorado em Engenharia de Transportes) - Escola de Engenharia, Universidade de São Paulo, São Paulo, 2010.

AHUVIA, A. Beyond the Extended Self: Loved Objects and Consumers' Identity Narratives. Journal of Consumer Research, v. 32, p. 171-184, 2005.

ALDRIDGE, J. Picture this: the Use of Participatory Photographic Research Methods with People with Learning Disabilities. Disability \& Society, v. 22, n. 1, p. 1-17, 2007.

ARNOULD, E.; THOMPSON, C. Consumer Culture Theory (CCT): Twenty Years of Research, Journal of Consumer Research, v. 31, p. 868-882, March 2005.

AUDIRAC, I. Accessing Transit as Universal Design. Journal of Planning Literature, v. 23, n. 1, p. 4-16, 2008.

BARDIN, L. Análise de conteúdo. Lisboa: Edições 70, 2011.

BAUER, M. A análise de conteúdo clássica: uma revisão. In: BAUER, M.; GASKELL, G. Pesquisa qualitativa com texto, imagem e som: um manual prático. Petrópolis: Vozes, 2002, p. 189-217.

BAUMAN, Z. Vida para consumo: a transformação das pessoas em mercadoria. Rio de Janeiro: Jorge Zahar, 2008.

BOURHIS, G.; HORN, O.; HABERT, O.; PRUSKI, A. An Autonomous Vehicle for People with Motor Disabilities. Robotics \& Automation Magazine, v. 8, n. 1, p. 20-28, 2002.

BRASIL. Resolução n. 454, de 25 de abril de 2015. Entidades de Fiscalização do Exercício das Profissões Liberais. CONSELHO FEDERAL DE FISIOTERAPIA E TERAPIA 
OCUPACIONAL. Diário Oficial [da] República Federativa do Brasil, Brasília, DF, 14 de maio de 2015.

BROMLEY, R.; MATTHEWS, D.; THOMAS, C. City Centre Accessibility for Wheelchair Users: the Consumer Perspective and the Planning Implications. Cities, v. 24, n. 3, p. 229$241,2007$.

CAMBIAGHI, S. Desenho universal: métodos e técnicas para arquitetos e urbanistas. São Paulo: Editora Senac, 2007.

CAMPOS, J.; VASCONCELLOS, E.; KRUGLIANSKAS, G. Incluindo pessoas com deficiência na empresa: estudo de caso de uma multinacional brasileira. Revista de Administração, v. 48, n. 3, p. 560-573, 2013.

CARROLL, K.; GROSS, K. An Examination of Clothing Issues and Physical Limitations in the Product Development Process. Family and Consumer Sciences Research Journal, v. 39, n. 1, p. 2-17, 2010.

CHANG, H.; YURCHISIN, J.; HODGES, N.; WATCHRAVESRINGKAN, K.; ACKERMAN, T. An Investigation of Self-Concept, Clothing Selection Motivation, and Life Satisfaction Among Disabled Consumers. Family and Consumer Sciences Research Journal, v. 42, n. 2, p. 162-176, 2013.

CROCKETT, D.; DOWNEY, H.; FIRAT, A.; OZANNE, J.; PETTIGREW, S. Conceptualizing a Transformative Research Agenda. Journal of Business Research, v. 66, n. 8, p. 1171-1178, 2013.

CROOKS, V.; DORN, M.; WILTON, R. Emerging Scholarship in the Geographies of Disability. Health \& Place, v. 14, p. 883-888, 2008.

CROSBY, E. Exploring Stigma, Identity Gaps, and Consumption. 2012. 207 folhas. Tese de (Doutorado em Administração) - Departamento de Business Administration da University of Illinois at Urbana-Champaign, Illinois, 2012. 
DARCY, S. Inherent Complexity: Disability, Accessible Tourism and Accommodation Information Preferences. Tourism Management, v. 31, n. 6, p. 816-826, 2010.

FARIA, M; CARVALHO, J. Diretrizes para pesquisas com foco em pessoas com deficiência: um estudo bibliométrico em administração. Revista Ciências Administrativas, v. 19, n. 1, p. 35-68, 2013.

FARIA, M.; SILVA, J. Desinteresse em atender as demandas das pessoas com deficiência visual: foco nas experiências de consumo em restaurantes. In: ENCONTRO DA ASSOCIAÇÃO NACIONAL DE PÓS-GRADUAÇÃO E PESQUISA EM ADMINISTRAÇÃO, 35. Anais... Rio de Janeiro: Anpad, 2011.

GANT, R. Shopmobility at the Millennium: 'Enabling' Access in Town Centres. Journal of Transport Geography, v. 10, n. 2, p. 123-133, 2002.

GOFFMAN, E. Estigma: notas sobre a manipulação da identidade deteriorada. 4. ed. Rio de Janeiro: LTC, 2008.

GOODRICH, R.; RAMSEY, M. Are Consumers with Disabilities Receiving the Services They Need? Journal of Retailing and Consumer Services, v. 19, n. 1, p. 88-97, 2012.

HALL, E.; KEARNS, R. Making Space for the 'Intellectual'in Geographies of Disability. Health \& Place, v. 7, n. 3, p. 237-246, 2001.

HANASHIRO, D.; GODOY, A. Um preâmbulo à gestão da diversidade: da teoria à prática. In: ENCONTRO DA ASSOCIAÇÃO NACIONAL DE PÓS-GRADUAÇÃO e PESQUISA EM ADMINISTRAÇÃO, 28, 2004. Anais... Curitiba: Anpad, 2004.

HANISCH, H. Disabled Adolescence - Spaces, Places and Plans for the Future: a Case Study. European Journal of Disability Research, v. 5, n. 2, p. 93-103, 2011.

HEATH, T.; CHATZIDAKIS, A. The Transformative Potential of Marketing from the Consumers'point of View. Journal of Consumer Behaviour, v. 11, n. 4, p. 283-291, 2012. 
IMRIE, R. Demystifying Disability: a Review of the International Classification of Functioning, Disability and Health. Sociology of Health \& Illness, v. 26, n. 3, p. 287-305, 2004.

IWARSSON, S.; STAHL, A. Accessibility, Usability and Universal Design Positioning and Definition of Concepts Describing Person-Environment Relationships. Disability \& Rehabilitation, v. 25, n. 2, p. 57-66, 2003.

JASPER, C.; WALDHART, P. Employer Attitudes on Hiring Employees with Disabilities in the Leisure and Hospitality Industry: Practical and Theoretical Implications. International Journal of Contemporary Hospitality Management, v. 25, n. 4, p. 577-594, 2013.

KAUFMAN-SCARBOROUGH, C. Retailers' Perceptions of the Americans with Disabilities Act: Suggestions For Low-Cost, High Impact Accommodations for Disabled Shoppers. Journal of Consumer Marketing, v. 15, n. 2, p. 94-110, 1998.

KENYON, S.; LYONS, G.; RAFFERTY, J. Transport and Social Exclusion: Investigating the Possibility of Promoting Inclusion Through Virtual Mobility. Journal of Transport Geography, v. 10, n. 3, p. 207-219, 2002.

KONRAD, A.; MOORE, M.; DOHERTY, A.; NG, E.; BREWARD, K. Vocational Status and Perceived Well-Being of Workers with Disabilities. Equality, Diversity and Inclusion: An International Journal, v. 31, n. 2, p. 100-123, 2012.

LANGAN, C. Mobility Disability. Public Culture, v. 13, n. 3, p. 459-84, 2001.

LAVILLE, C.; DIONNE, J. A construção do saber: manual de metodologia de pesquisa em ciências humanas. Porto Alegre: Artmed, 1999.

LE BRETON, D. Adeus ao corpo: antropologia e sociedade. 4. ed. Campinas: Papirus, 2009.

LIMA, M.; VASCONCELOS, N.; BRITO, M.; CAPPELLE, M. O sentido do trabalho para pessoas com deficiência. Revista de Administração Mackenzie, v. 14,n. 2, p. 42-68, 2013. 
LOIZOS, P. Vídeo, filme e fotografias como documentos de pesquisa. In: BAUER, M.;

GASKELL, G. Pesquisa qualitativa com texto, imagem e som: um manual prático. Petrópolis: Vozes, 2002, p. 137-155.

MAIA, F.; NIEMEYER, L.; FREITAS, L. Tecnologia assistiva: entendendo o processo.

Caderno Seminal Digital, v. 13, n. 13, p. 63-73, jan.-jun. 2010.

MALHOTRA, N. Pesquisa de marketing. 4. ed. Porto Alegre: Bookman, 2006.

MANZINI, E. Tecnologia assistiva para educação: recursos pedagógicos adaptados. In: Secretaria de Educação Especial. Ensaios pedagógicos: construindo escolas inclusivas. Brasília: SEESP/MEC, 2005. p. 82-86.

McCRACKEN, G. Cultura e consumo: uma explicação teórica da estrutura e do movimento do significado cultural dos bens de consumo. Revista de Administração de Empresas, v. 47, n. 1, p. 99-115, jan./mar. 2007.

MELO, F. Proposição de Medidas Favorecedoras à Acessibilidade e Mobilidade de Pedestres em Áreas Urbanas. Estudo de Caso: O Centro de Fortaleza. Dissertação de Mestrado, Programa de Mestrado em Engenharia de Transportes. Orientadora: Maria Elisabeth Pinheiro Moreira. Universidade Federal do Ceará, Fortaleza, 2005.

MENDONÇA, R.; BARBOSA, M.; DURÃO, A. Fotografias como um recurso de pesquisa em marketing: o uso de métodos visuais no estudo de organizações de serviços. Revista de Administração Contemporânea, v. 11, n. 3, p. 57-81, 2007.

MERTENS, D. Research and Evaluation in Education and Psychology: Integrating Diversity With Quantitative, Qualitative, And Mixed Methods. 3. ed. California: Sage, 2009.

MERTENS, D. Transformative Considerations: Inclusion and Social Justice. American Journal of Evaluation, v. 28, n. 1, p. 86-90, 2007.

MICK, D. Meaning and Mattering through Transformative Consumer Research. Advances in Consumer Research. v. 33, n. 1, p. 1-4, 2006. 
MONACELli, E.; DUPIN, F.; DUMAS, C.; WAGSTAFF, P. A Review of the Current

Situation and Some Future Developments to Aid Disabled and Senior Drivers in France. Ingénierie et Recherche Biomédicale, v. 30, n. 5/6, p. 234-239, 2009.

NEIVA-SILVA, L.; KOLLER, S. O uso da fotografia na pesquisa em psicologia. Estudos de Psicologia, v. 7, n. 2, p. 237-250, 2002.

NICHOLL, A. O ambiente que promove a inclusão: conceitos de acessibilidade e usabilidade. Revista Assentamentos Humanos, v. 3, n. 2, p. 49-60, 2001.

OZANNE, J.; DESCHENES, J. Workbench Issues in Transformative Consumer Research. Advances in Consumer Research, v. 34, n. 1, p. 20-24, 2007.

PACE, S. Does Religion Affect the Materialism of consumers? An Empirical Investigation of Buddhist Ethics and the Resistance of the Self. Journal of Business Ethics, v. 112, n. 1, p. 25-46, 2013.

POMERING, A.; JOHNSON, L.; NOBLE, G. Advertising Corporate Social Responsibility: Results from an Experimental Manipulation of Key Message Variables. Corporate Communications: An International Journal, v. 18, n. 2, p. 249-263, 2013.

PORIA, Y.; REICHEL, A.; BRANDT, Y. Dimensions of hotel experience of people with disabilities: an exploratory study. International Journal of Contemporary Hospitality Management, v.23, n.5, p.571-591, 2011.

PRASAD, R.; HUNTER, J.; HANLEY, J. Driving Experiences of Disabled Drivers. Clinical Rehabilitation, v. 20, n. 5, p. 445-450, 2006.

RESENDE, M.; CAVALCANTI, A.; ANDRADE, V. Veículo adaptado: caracterização de suas adaptações e do perfil de seus condutores. Cadernos de Terapia Ocupacional, v. 20, n. 1, p. 73-80, 2012. 
SASSAKI, R. Inclusão e no lazer e turismo: em busca da qualidade de vida. São Paulo: Áurea, 2003.

SCHMÖCKER, J.; QUDDUS, M.; NOLAND, R.; BELL, M. Mode Choice of Older and Disabled People: a Case Study of Shopping Trips in London. Journal of Transport Geography, v. 16, n. 4, p. 257-267, 2008.

SCHULZE, S. The Usefulness Of Reflexive Photography for Qualitative Research: a Case Study in Higher Education. South African Journal of Higher Education, v. 21, n. 5, p. 536$553,2007$.

SHAND, J.; SIVEWRIGHT, J. Car Driving for the Severely Physically Disabled: the American Experience. Paraplegia, v. 32, n. 10, p. 697-699, 1994.

SHI, L.; COLE, S.; CHANCELLOR, H. Understanding Leisure Travel Motivations of Travelers with Acquired Mobility Impairments. Tourism Management, v. 33, n. 1, p. 228$231,2012$.

SMITH, E. Pimp my Wheelchair!: The Supply and Demand For Personalized Wheelchairs. Explorations, v. 8, p. 17-32, 2005.

TAKAMIYA, S.; HAMADA, S. Information Used by Visually Impaired People While Walking. Transportation Research Record, n. 1636, p. 104-109, 1998.

TETTE, R.; CARVALHO-FREITAS, M.; OLIVEIRA, M. Deficiência e trabalho: relações entre significado do trabalho e percepção de suporte organizacional. In: ENCONTRO DA ASSOCIAÇÃO NACIONAL DE PÓS-GRADUAÇÃO E PESQUISA EM ADMINISTRAÇÃO, 37. Anais... Rio de Janeiro: Anpad, 2013.

WANG, W.; COLE, S. Perceived Onboard Service Needs of Passengers with Mobility Limitations: an Investigation among Flight Attendants. Asia Pacific Journal of Tourism Research, v. 18, n. 8, p. 934-946, 2013. 
WHITE, M.; MARSH, E. Content Analysis: a Flexible Methodology. Library Trends, v. 55, n. 1, p. 22-45, 2006.

WITT, U. Symbolic Consumption and the Social Construction of Product Characteristics. Structural Change and Economic Dynamics, v. 21, n. 1, p. 17-25, March 2010.

WOODRUM, E. "Mainstreaming" Content Analysis in Social Science: Methodological Advantages, Obstacles, and Solutions. Social Science Research, v. 13, n. 1, p. 1-19, 1984. 